\title{
Editorial overview: Energy intensification using thermal storage
}

TF Edgar ${ }^{1,2}$ and KM Powell ${ }^{1}$

${ }^{1}$ McKetta Department of Chemical Engineering, University of Texas, 200 E. Dean Keeton St., Austin, TX 78712, USA

${ }^{2}$ Energy Institute at the University of Texas, 2304 Whitis Avenue, Austin, TX 78712, USA

Email: edgar@che.utexas.edu

Phone: 512-471-3080

Fax: 512-471-7060

\begin{abstract}
Thermal energy storage (TES) is a cost-effective technology that can greatly improve the performance of energy systems that have dynamic supply or demand. In solar thermal systems, TES plus controls enables the power output of the plant to be intensified and effectively regulated, despite fluctuating solar irradiance. In district energy systems, TES can be used to shift loads, allowing the system to take advantage of variable energy prices. The benefit of TES can be significantly enhanced by dynamically optimizing the complete energy system. The ability of TES to shift loads gives the system new degrees of freedom that can be exploited to yield optimal performance and improve thermal efficiency.

\section{Introduction}

EPA's recently proposed Clean Power Plan represents a major push to reduce greenhouse gas emissions and to increase energy security. Significant focus has been given to energy efficiency improvements and to the development of renewable energy such as solar PV, wind, and biomass. Although renewable energy penetration and energy efficiency have grown considerably during the past two years in the power sector, the majority of the electrical energy in the United States still comes from coal and natural gas.
\end{abstract}

Although renewable energies are abundant, their intermittency puts them at a disadvantage compared to fossil fuels. With energy storage, energy can be accumulated during periods of excess and then dispatched as necessary to meet demands, which alleviates the intermittency issue and makes renewable resources like solar and wind much more viable [1]. Many different forms of energy storage exist including battery storage, pumped hydro, compressed air, and thermal energy storage, but this introduces a dynamic aspect to energy management, in order to intensify the energy available for delivery.

Energy storage can intensify renewable energy systems, but also conventional systems. Because energy storage allows a system to shift times of energy production or consumption, it has shown great potential in improving the overall efficiency of conventional energy systems as well. The grid demand for power can vary during a 24 hour period by a factor of two. Thus energy storage gives a baseload system the ability to store excess energy when production capacity exceeds demand, then use this stored energy 
dynamically for periods of higher demand, thereby reducing the required size of the system and yielding operational cost savings.

Thermal energy storage (TES) is the storage of thermal energy as latent heat, sensible heat, or chemical heat. In warmer climates TES is often used for storing "cooling" in the form of chilled water or ice, usually in a large tank. This tank can be used to store cold water when demand is low, and then the water can be discharged when demand is high in order to meet cooling loads. Though not as versatile as battery storage, TES is much cheaper with costs ranging from $\$ 6-43 / \mathrm{kWh}[2,3]$. Battery costs range from $\$ 74-1484 / \mathrm{kWh}[4]$. TES is a promising technology due to its low cost, particularly in comparison to battery storage [5]. TES has been used in a wide array of applications including concentrated solar power (CSP), electric grid storage, space heating and cooling, and combined heat and power (CHP). Although successful implementations of TES in multiple sectors have proven this technological and economic viability, performance can be improved by focusing on optimal dynamic management of the resource.

Combined heat and power (CHP, also called cogeneration) is the simultaneous production of heat and electricity. These power plants use gas and steam turbines in a combined cycle to generate electricity. CHP currently produces about one-fourth of the power in the process industries. CHP systems typically have very high efficiencies ( $70-80 \%)$ compared to electricity-only steam turbine systems $(\sim 35 \%)$ and can be integrated with building climate control systems by using chillers. CHP systems most often include a natural gas turbine, but systems such as fuel cells, reciprocating engines, and microturbines are also ideal CHP candidates [6].

District cooling allows a centralized chiller plant to provide cooling to a number of facilities in a single geographical area and benefit from economies of scale. The cooling district can comprise industrial facilities, commercial facilities, residential facilities, or any combination of the above. District cooling (and heating) networks can generally improve overall system efficiency when compared to a distributed cooling system $[7,8]$. However, they do require significantly more infrastructure than distributed systems. Solar district heating can also be done on a seasonal basis, where solar energy is collected in the summer months, used to heat an underground storage system (such as a section of earth), then extracted in winter months for space heating [9].

Electricity generation systems are required to vary their power output to match consumer demand. Systems relying on intermittently available energy, such as solar and wind power, are heavily influenced by the varying energy source. Thus, for determining optimal operation of the system, it becomes critical for these types of systems to employ forecasting to predict and account for major exogenous disturbances. These forecasts could include: weather, pricing, and demand, which are important when longer time scales of optimal operation are considered. Typically a day-ahead forecast is sufficient, but longer periods may be required in certain cases. When accurate forecasting models are combined with dynamic systems-level models of energy systems with storage, many opportunities arise for dynamic optimization. The extra degrees of freedom that accompany energy storage can then be fully exploited [10]. 
Two vignettes illustrating dynamic optimization for energy storage are presented here. The first system, solar thermal power with storage, follows a distinct diurnal cycle. By using modeling and control of storage, an intermittent input can be converted into a constant power output. Additionally, storage can be further exploited by adding in storage bypass, solar radiation forecasting, and hybrid solar/gas operation and using these features in a dynamic optimization solution. A second example involves the University of Texas CHP plant combined with a TES system. Here the cooling loads are forecasted using empirical models which are developed from historical load and weather data. The campus meets all of its own electrical, heating, and cooling needs and is the largest microgrid (125 MW) in the U.S. Because the cooling system requires large amounts of electricity, the cooling/TES and CHP systems are highly interdependent. This will require forecasts of electrical, heating, and cooling loads with the objective being to minimize the campus energy usage and operating costs.

\section{Modeling and Control of a Solar Thermal Plant with Storage}

Solar thermal energy makes effective use of solar energy by converting it directly to heat. The ease with which energy can be collected and stored via TES makes solar thermal processes viable for power production. Because of its ability to act as a buffer for intermittent renewable resources, high temperature TES is an enabling technology for concentrating solar power (CSP) systems used for electricity generation [11]. The high temperatures are achieved by concentrating the solar radiation to heat a fluid with parabolic collectors, then using this fluid to generate steam, which is then fed to a turbine, ultimately converting sunlight into electricity [12-15].

If constant (baseload) power generation is the objective, the low cost of TES gives CSP a current advantage over photovoltaic (PV) systems, which must rely on expensive battery storage to achieve the same baseload level as CSP systems. However, the costs of batteries such as lithium-ion are projected to decrease over the next 10 years. In addition, the cost of PV generation has been decreasing rapidly over the past several years, and as of 2015 has declined to under 4 cents/kWh for utility-scale PV (based on news reports). Therefore PV plus battery storage will likely be the preferred option for baseload solar power generation in 2030 .

A first principles model of a solar thermal power plant with high temperature TES was developed by Powell and Edgar [16]. The model uses a two-tank direct configuration for energy storage, where a fluid such as Dowtherm is used for heat collection and storage (see Fig. 1). The temperatures of the hot and cold tanks are $390^{\circ} \mathrm{C}$ and $250^{\circ} \mathrm{C}$, respectively. 


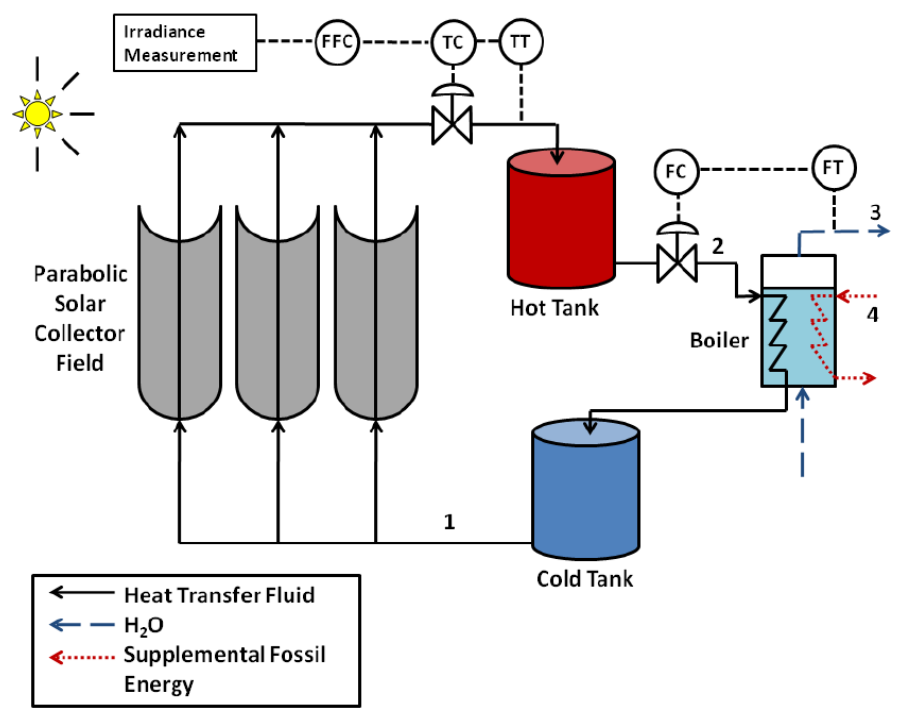

Figure 1: Diagram of the solar power plant with storage and the control scheme. Fluid flows from the cold tank, through the collector field, where it is heated by concentrated sunlight, to the hot tank. From the hot tank, it flows through the boiler, where it generates steam before being delivered back to the cold tank.

The study considered several scenarios: with and without energy storage on both a sunny day and a day with sporadic cloud cover. The study demonstrated the value of TES for operation of a solar thermal power plant. Despite using a relatively simple control system (a feedforward plus feedback controller for solar field temperature control by manipulating the flowrate and a feedback-only controller for power control), the power output of the plant can be controlled to a constant rate. By contrast, a system without thermal energy storage undergoes large fluctuations in output power because it is entirely subject to availability of solar energy. The storage system, therefore, provides an invaluable buffer between available solar energy and energy demand. With the addition of a feedback plus feedforward control system for the fluid temperature by manipulating the flowrate, the system is able to maintain a constant power output. This allows the system to operate much more stably without having to attempt to rapidly ramp the backup energy source up and down to make up for any power discrepancy, thereby using less natural gas.

TES helps increase the solar share (fraction of energy provided by solar) of the plant. Using simulation [16], on clear days the solar share is much larger for a system with TES, which requires $43 \%$ less supplemental energy. The differences in the solar share on the cloudy day are minor, but the most crucial benefit of a system with TES is its ability to produce a constant power output, despite a widely fluctuating input. The remainder of the energy is assumed to be provided by the supplementary natural gas. Adding a control strategy improves efficiency even more. Three scenarios shown in Table 1 were considered using a model-based controller and weather forecasts: sunny, partly cloudy, and mostly cloudy, with the objective to minimize the amount of fossil fuel used. The dynamic optimization strategy improves the amount of solar energy collected in each scenario, although it performs best on a mostly cloudy day, increasing the total solar energy collected by about two-thirds, while having only a modest impact on the sunny and partly cloudy days. 
Table 1: Summary of results for the standard control scheme compared to the dynamic optimization with forecast scheme (1 MW thermal output for a 24 hour period).

\begin{tabular}{|r|c|c|}
\hline & $\begin{array}{c}\text { Solar Energy Collected } \\
\text { (MWh) }\end{array}$ & $\begin{array}{c}\text { Energy Collected/ Total Incident } \\
\text { Energy (\%) }\end{array}$ \\
\hline Sunny Day & & $77 \%$ \\
\hline Standard Control & 18.0 & $79 \%$ \\
\hline Partly Cloudy Day & 18.6 & $76 \%$ \\
\hline Standard Control & 14.6 & $81 \%$ \\
\hline Dynamic Optimization & 15.8 & $52 \%$ \\
\hline Mostly Cloudy Day & & $85 \%$ \\
\hline Standard Control & 4.8 & \\
\hline Dynamic Optimization & 7.8 & \\
\hline
\end{tabular}

\section{District Cooling with Thermal Energy Storage}

District energy storage is fairly common in Europe $[17,18]$ but is now receiving more attention in the U.S. [19]. The University of Texas at Austin has a district cooling network, which circulates chilled water to each building on campus in order to meet campus cooling needs. This network includes four chilling stations located at various points throughout campus, which can be used collectively to meet the campus's cooling requirements. In 2014, the university installed a TES system, which is used to offset the cost of additional chilling equipment by allowing current equipment to operate during off-peak hours, store the extra energy produced, and use this energy to cool the campus during peak periods later.

Due to the recent installation of the TES system, a time-of-day operating strategy for its use has not yet been implemented. The chilling system is currently run by an experienced operator, who carefully monitors the current load and tries to deduce which chillers to bring on and when. Due to equipment constraints, it is generally not advisable to frequently turn the chillers on and off. Thus, it is important to commit to keeping a chiller on for several hours if it is to be turned on. Chiller 1 is a variable frequency chiller (able to meet variable loads) with a range of $20-30 \%$ of the campus maximum cooling load. Chillers 2, 3, and 4 are constant frequency drive chillers of different ages and efficiencies. Chillers 2 and 4 have a capacity of $30 \%$ and $40 \%$, respectively, of the campus maximum load (based on the past year of operation) and Chiller 3 , the least efficient chiller, has a capacity of $10 \%$ of the campus maximum load. When an operator is unaware of what the total load may be several hours in advance, he or she may turn on Chiller 3, thinking that the maximum daily load will not exceed the combined capacity of Chillers 1, 3 and 4. However, with no expectations for the predicted load, it becomes necessary later in the day to turn on Chiller 2, which is not optimal.

If the objective is to minimize total energy consumption over some time horizon by optimally placing the cooling load on certain chillers at suitable times of the day, the addition of thermal energy storage to a cooling network adds more degrees of freedom. Using energy storage, cooling loads can be shifted, not only to the most efficient chillers, but to the times of the day when chillers operate most efficiently, typically when ambient wet bulb temperatures are lower [20]. While the extra degrees of freedom 
provided by energy storage are very useful, they also make the problem much more difficult to solve. This dynamic optimization problem is discretized temporally into one hour periods over a 24 hour day. Figure 2 shows the results of dynamic optimal chiller loading [21] with three cases studied. Case (a) is the current operator-based approach (no optimization). Case (b) uses load forecasting (based on weather forecasts) and optimization of the four chillers, and Case (c) adds thermal energy storage (TES) to the operating strategy. In Case (b), chiller 3 is turned off, while in Case (c), neither chiller 2 or 3 is used, relying on the two most efficient chillers 1 and 4 . An added benefit of storage is that it allows the chillers to run at a more constant rate for the duration of the day, with only small fluctuations in the load on each chiller.
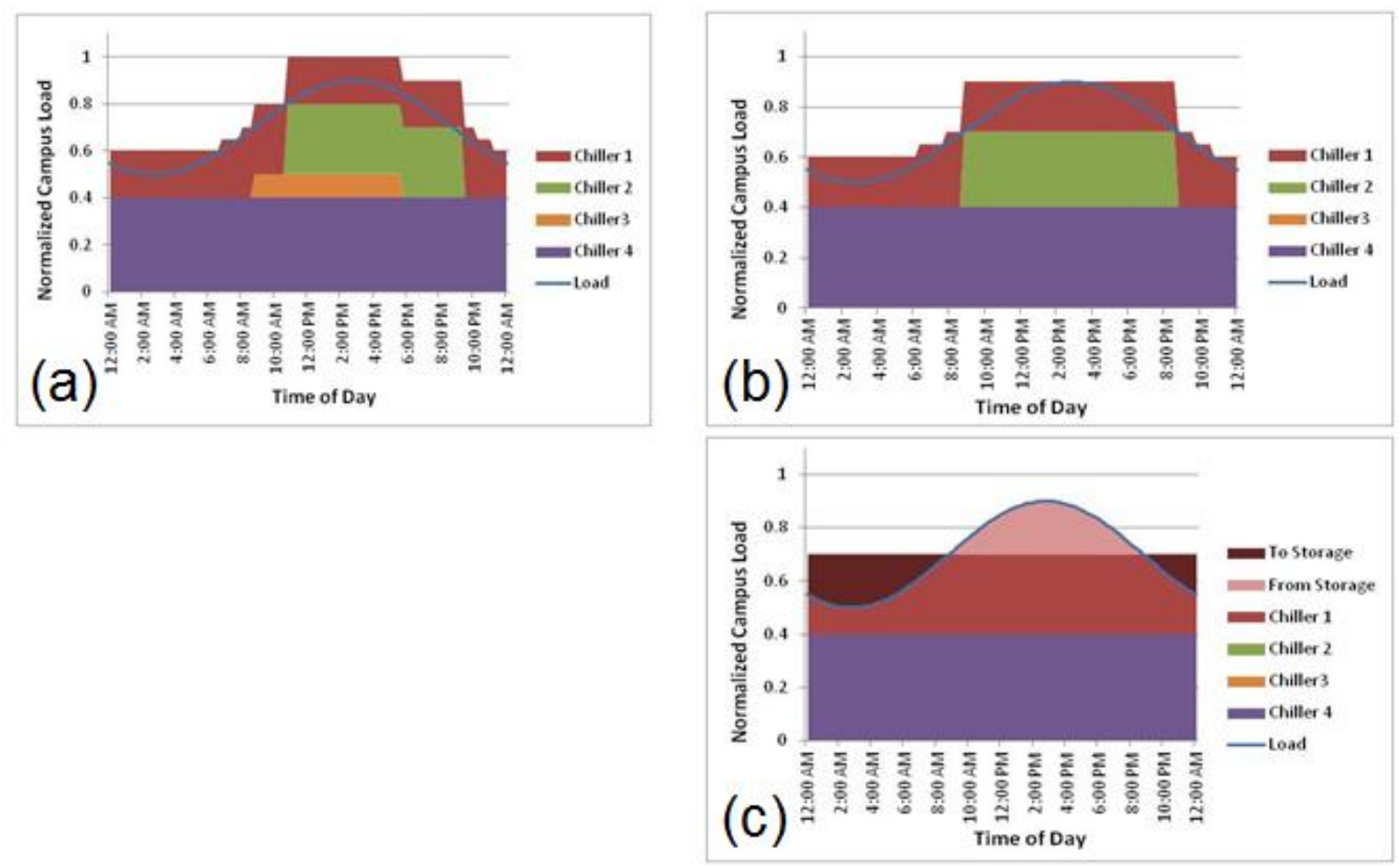

Figure 2: Thermal Energy Storage Operating Strategy with Four Chillers a) Experienced-based (operator-initiated); b) Load forecasting + optimization; c) Load forecasting + TES + optimization

Table 2 summarizes the results of three different days used in this case study and shows that the total energy consumption is improved by a total of up to $9.4 \%$ in going from an equal ratio chiller loading strategy (recommended by vendors) to a dynamic optimal chiller loading strategy with thermal energy storage [22]. In Case 3, a day when there is less than one degree fluctuation in ambient wet bulb temperature, the savings are $6.8 \%$. Therefore, the benefit of using thermal energy storage for shifting cooling loads to more efficient periods of the day depends on how much ambient conditions change during the day. 
Table 2: Summary of three different cases for minimizing chiller energy consumption. Case 1: equal ratio chiller loading (where each chiller is assigned the same ratio of load with respect to its maximum capacity), Case 2: static optimal chiller load, and Case 3: dynamic optimal chiller loading using storage.

\begin{tabular}{|l|c|c|c|}
\hline & Case 1 & Case 2 & Case 3 \\
\hline T $_{\text {WB }}$ Range $\left({ }^{\circ} \mathbf{C}\right)$ & 6.4 & 5.6 & 0.9 \\
\hline Min Cooling Load (kW) & 37,900 & 39,600 & 62,500 \\
\hline Max Cooling Load $(\mathbf{k W})$ & 55,400 & 65,300 & 76,400 \\
\hline Total Energy Consumption (MWh) & & & \\
\hline Equal Ratio Chiller Loading & 166 & 198 & 280 \\
\hline Static Optimal Chiller Loading & 152 & 183 & 262 \\
\hline Dynamic Optimal Chiller Loading & 150 & 180 & 261 \\
\hline Total Savings & $\mathbf{9 . 4 \%}$ & $\mathbf{9 . 0 \%}$ & $\mathbf{6 . 8 \%}$ \\
\hline
\end{tabular}

To minimize the campus carbon footprint and energy costs, the cooling system should not be considered in isolation. Cooling demands are a large part of the electrical load, particularly in Texas, thus the campus generates steam from waste heat from the gas turbines and from supplemental, gas-fired boilers. Because of this waste heat integration, the electric and thermal loads are highly coupled. This creates a more complex optimization problem due to the highly integrated energy network.

For example, when the electrical output of the gas turbine increases, the waste heat output from this turbine also increases. The supplemental boiler rate must then be decreased accordingly to account for the excess heat generated in the heat recovery steam generator (HRSG). The UT CHP system also has turbine inlet cooling, where the turbine inlet air is cooled to improve throughput and efficiency of the turbine, which adds another coupling between the cooling network and the power plant. Because the campus independently supplies its own heat, cooling, and electricity, it is necessary to include each of these loads in the dynamic optimization problem. The objective is to minimize the campus total fuel costs, which is equivalent to minimizing the campus total carbon footprint (for the power plant).

Solving a 24-hour dynamic optimization problem for a CHP system requires forecasting of the disturbances (mainly the electric, cooling, and heating loads) as well as electric power prices for the grid [23]. Environmental conditions (i.e., temperature, relative humidity) also affect equipment performance, so forecasts of these variables are used. These forecasts can be obtained directly from a weather forecasting database, however, with little modeling effort required. The full UT power plant dynamic optimization has been addressed by Kim et al. [24, 25].

\section{Conclusion}

The two vignettes discussed in this paper demonstrate the benefits of optimal control combined with thermal energy storage in order to deal with dynamic power demand and/or intensify intermittent energy services. Both examples require modeling a diverse range of systems including the TES, the solar power plant, boilers, gas and steam turbines, heat recovery equipment, chillers, and pumps. These 
large-scale dynamic problems also require novel solution methods to determine the optimal design and management strategy so that the costs of storage are minimized and energy savings are maximized.

\section{Acknowledgments}

We thank National Science Foundation (IGERT 0966298), the University of Texas Green Fee Fund, Cockrell School of Engineering-Abell Endowed Chair, and Texas Instruments for financial support.

\section{References}

-1. Jacobson MZ, Delucchi MA, Bazouin G, Bauer ZAF, Heavey CC, Fisher E, Morris SB, Piekutowski DJY, Vencill TA, and Yeskoo TW: $\mathbf{1 0 0 \%}$ clean and renewable wind, water and sunlight (WWS) allsector energy roadmaps for the 50 United States. Energy and Environmental Science 2015, 8: 2093-2117.

This study presents roadmaps for each of the 50 United States to convert their all-purpose energy systems largely based on fossil fuels to ones powered entirely by wind, water, and sunlight. The plans contemplate $80-85 \%$ of existing energy replaced by 2030 and $100 \%$ replaced by 2050 .

2. Hasnain SM, Alawaji SH, Al-Ibrahim AM, and Smiai MS: Prospects of cool thermal storage utilization in Saudi Arabia. Energy Conversion and Management 2000, 41: 1829-1839.

3. Roth K, Zogg R, and Brodrick J: Cool thermal energy storage. ASHRAE Journal 2006, 48: 94-96.

4. Hou Y, Vidu R, and Stroeve P: Solar Energy Storage Methods. Industrial and Engineering Chemical Research 2011, 50: 8954-8964.

-5. Dincer I and Rosen M: Thermal Energy Storage: Systems and Applications. Wiley; 2010. This book covers recent energy efficient and sustainable technological methods and solutions for thermal energy storage (TES) systems analysis, design and performance improvement as well as lifecycle costing and assessment. The book provides the fundamental principles and practical applications of thermal energy storage technology.

-6. Chicco G and Mancarella P: Distributed multi-generation: A comprehensive view. Renewable and Sustainable Energy Reviews 2009, 13: 535-551.

The coupling of cogeneration systems to absorption/electric chillers or heat pumps, as well as the interactions with renewable sources, allow for cooling power, hydrogen, and various chemical substances. Benefits include higher energy efficiency, reduced $\mathrm{CO}_{2}$ emissions, and enhanced economy, utilizing a comprehensive distributed multi-generation framework for energy planning.

7. Chow TT, Fong KF, Chan ALS, Yau R, Au WH, and Cheng V: Energy modelling of district cooling system for new urban development. Energy and Buildings 2004, 36: 1153-1162.

8. Chow TT, Au WH, Yau R, Cheng V, Chan A, and Fong KF: Applying district-cooling technology in Hong Kong. Applied Energy 2004, 79: 275-289.

9. Pinel P, Cruickshank C, Beausoleil I, and Wills A: A review of available methods for seasonal solar thermal energy in residential applications. Renewable and Sustainable Energy Reviews 2011, 15: 3341-3359. 
$\bullet$ 10. Cole WJ, Powell KM, and Edgar TF: Optimization and advanced control of thermal energy storage systems. Reviews in Chemical Engineering 2012, 28: 81-99.

This paper reviews published literature on optimization and control of thermal energy storage systems. Emphasis is given to thermal storage applied to combined heat and power systems, building systems, and solar thermal power systems with special emphasis on applications in the chemical industry.

11. Gil A, Medrano M, Martorell I, Lazaro A, Dolado P, Zalba B, and Cabeza L: State of the art on high temperature thermal energy storage for power generation. Part I: Concepts, materials, and modellization. Renewable and Sustainable Energy Reviews 2010, 14: 31-55.

12. Camacho $E$, Rubio F, Berenguel M, and Valenzuela L: A survey on control schemes for distributed solar collector fields. Part II: Advanced control approaches. Solar Energy 2007 81: 1252-1272.

-13. Kuravi S, Trahan J, Goswami DY, Rahman MM, and Stefanakos EK: Thermal energy storage technologies and systems for concentrating solar power plants. Progress in Energy and Combustion Science 2013, 39: 285-319.

This paper reviews thermal energy storage system design methodologies and factors to be considered at different hierarchical levels for concentrating solar power plants. Different thermal energy storage system designs and thermal and exergy efficiency analyses are presented.

14. Menendez RP, Matinez JA, Prieto MJ, Barcia LA, and Martin Sanchez JM: A novel modeling of molten-salt heat storage systems in thermal solar power plants. Energies 2014, 7:6721-6740.

15. Medrano M, Gil A, Martorell I, Potau X, and Cabeza L: State of the art on high-temperature thermal energy storage for power generation. Part II: Case Studies. Renewable and Sustainable Energy Reviews 2010, 14: 56-72.

$\bullet$ 16. Powell KM and Edgar TF: Modeling and control of a solar thermal power plant with thermal energy storage. Chemical Engineering Science 2012, 71: 138-145.

Dynamic simulation results for a thermal energy storage unit used in a parabolic trough concentrated solar power system are presented using a two-tank-direct method for the thermal energy storage. The use of storage gives the system the ability to provide power at a constant rate despite significant disturbances in the amount of solar radiation available.

-17. Nuytten T, Claessens B, Paredis K, Van Bael J, and Six D: Flexibility of a combined heat and power system with thermal energy storage for district heating. Applied Energy 2013, 104: 583-591.

A model is presented that determines the theoretical maximum of flexibility of a combined heat and power system coupled to a thermal energy storage solution that can be either centralized or decentralized. The amount of flexibility created in the district heating system is determined by the approach of the system through delayed or forced operation mode. 
18. Gadd $\mathrm{H}$ and Werner S: Daily heat load variations in Swedish district heating systems. Applied Energy 2013, 106: 47-55.

-19. Siirola JJ and Edgar TF: Process energy systems: control, economic, and sustainability objectives. Computers and Chemical Engineering 2012, 47: 134-144.

This paper discusses the current plant environment and how various metrics (sustainability or profitability) can be aligned by focusing on energy efficiency. Power-steam systems are the major energy drivers for most plants, and possible operational changes and control strategies to improve energy efficiency are discussed.

20. Mago PJ, Luck R, and Knizley A: Combined heat and power systems with dual power generation units and thermal storage. International Journal of Energy Research 2014, 38: 896907.

$\bullet$ 21. Powell KM, Cole WJ, Ekarika UF, and Edgar TF: Optimal chiller loading in a district cooling system with thermal energy storage. Energy 2013, 50: 445-453.

A dynamic optimal chiller loading method reduces the complexity of the dynamic problem by considering all chillers to be a single, optimal chiller. The static optimization problem is solved by choosing the best solution from a series of convex quadratic programming problems, thus ensuring global optimality at each time interval, and this is applied to a district cooling system in Austin, TX.

22. Kapoor K, Powell KM, Cole WJ, Kim JS, and Edgar TF: Improved large-scale process cooling operation through energy optimization. Processes 2013, 1: 312-329.

23. Moradi $\mathrm{MH}$, Hajinazari M, Jamasb $\mathrm{S}$, and Paripour M: An energy management system (EMS) strategy for combined heat and power (CHP) systems based on a hybrid optimization method employing fuzzy programming. Energy 2013, 49: 86-101.

-24. Kim JS and Edgar TF: Optimal scheduling of combined heat and power plants using mixedinteger nonlinear programming. Energy 2014, 77: 675-690.

MINLP (mixed-integer nonlinear programming) is applied for scheduling of a combined heat and power (CHP) plant in the day-ahead wholesale energy markets. This work employs first principles models to describe the nonlinear dynamics of a CHP plant and its individual compnenets and accounts for the different operating modes (synchronization, soak, dispatch, and desynchronization) during start-up and shut-down of each unit.

25. Kim JS, Powell KM, and Edgar TF: Nonlinear model predictive control for a heavy-duty gas turbine power plant. Process American Control Conference 2013, 2958-2963. 